\title{
FAIR TRADE E ECONOMIA COLABORATIVA COMO MECANISMOS DE PERSECUÇÃO DA JUSTIÇA SOCIAL
}

\author{
Daniela Ferreira Dias Batista ${ }^{1}$ \\ Vinícius Mendes e Silva ${ }^{2}$
}

\begin{abstract}
RESUMO
A ordem econômica constitucional exige que as empresas atuem conforme os ditames da justiça social, obedecendo a função social e solidária durante sua atividade. Neste sentido, o sistema do fair trade - comércio justo, que garante um equilíbrio no mercado, quanto ao preço, produção sustentável e com preocupação socioeconômica, bem como a economia colaborativa, que tem por ideal o compartilhamento, ao invés da posse, permitindo um maior acesso da sociedade aos bens de consumo e serviços, com menores custos ambientais e sociais, mostram-se como instrumentos eficazes da persecução da justiça social, na exata medida do que prevê o texto constitucional.
\end{abstract}

Palavras-chave: Economia colaborativa; Ordem econômica; Fair trade; Comércio justo; Justiça social.

\section{FAIR TRADE AND COLLABORATIVE ECONOMY AS MECHANISMS FOR THE PERSECUTION OF SOCIAL JUSTICE}

\begin{abstract}
The constitutional economic order requires that companies act according to the dictates of social justice, obeying the social and solidarity function during their activity. In this sense, the fair trade system, which guarantees a balance in the market, as regards price, sustainable production and with socioeconomic concern, as well as the collaborative economy, which is ideal for sharing, rather than ownership, allowing a greater access of society to consumer goods and services, with lower environmental and social costs, are seen as effective instruments for the pursuit of social justice, to the exact extent provided by the constitutional text.
\end{abstract}

Keywords: Collaborative economics; Economic order; Fair trade; Fair trade; Social justice.

\section{INTRODUÇÃO}

A proposta do presente trabalho é analisar os sistemas do fair trade (comércio justo) e da economia colaborativa, como mecanismos de persecução da justiça social, pesquisando

\footnotetext{
${ }^{1}$ Mestre em Direito pelo Centro Universitário Eurípides de Marília - UNIVEM. Professora da disciplina de Direito do Consumidor do Centro Universitário Eurípides de Marília - UNIVEM e da Fundação Educacional Miguel Mofarrej - Faculdades Integradas de Ourinhos - FIO. Membro do Grupo de Pesquisa "A intervenção do Poder Público na vida do indivíduo". Realiza pesquisa na área de Direito do Consumidor. Advogada, especialista pela UEL - Universidade Estadual de Londrina/PR.

${ }^{2}$ Advogado. Especialista em Direito Público pela EPD - Escola Paulista de Direito. Mestrando em Direito pela Universidade de Marília - UNIMAR.
} 
seus reflexos no mercado e na sociedade em geral, bem como qual o papel da empresa, em razão de sua função social e solidária, em obediência ao texto constitucional.

A economia colaborativa no sistema de fair trade busca a melhora na qualidade de vida dos envolvidos e dos que estão ao seu redor, visto que na realidade social em que vivemos, o consumo de produtos e serviços representa a inclusão social, pois a condição de consumidor ativo no mercado traz a cada pessoa a realização máxima de sua liberdade e dignidade, podendo usufruir dos benefícios do mercado globalizado, satisfazendo suas necessidades e seus desejos.

Para tanto, estuda-se, no primeiro capítulo, o sistema do fair trade - comércio justo, em linhas gerais, a sua origem e conceito, bem como os princípios que o sustenta, o método de atuação e sua função na busca pela justiça social.

No segundo capítulo, a abordagem é do fenômeno da economia colaborativa, partindo da análise do consumo compartilhado e da preocupação com questões socioambientais. Com isso, a ideia de possuir abre espaço para o dividir/compartilhar, em atendimento aos reclamos de uma sociedade moderna, mais ativa nas questões de sustentabilidade e problemas sociais, em busca dos ditames da justiça social.

Já o terceiro capítulo é dedicado ao estudo da função social e solidária da empresa, especialmente em decorrência do texto constitucional que inaugura a ordem econômica, com vistas à proteção da dignidade da pessoa humana. Apresentando como a empresa deve atuar para conformar-se com o texto constitucional, buscando, sempre, o melhor para a sociedade.

Objetiva-se com o presente estudo demonstrar que, a par da necessidade da empresa buscar sempre o lucro, é possível que ela, também, atue com fins sociais e solidários, como proposto pelos métodos do fair trade e da economia colaborativa.

O estudo justifica-se pelas necessidades ambientais, sociais e econômicas impostas à sociedade, o que pode gerar prejuízos para ela e, inclusive, para as gerações futuras, havendo, ainda, poucos estudos explorando a matéria. O estudo tem abordagem teórica, através de pesquisa qualitativa e descritiva, com o método dedutivo, na medida em que houve uma análise dos sistemas do fair trade, da economia colaborativa e da função social e solidária da empresa, com referência na teoria desenvolvida por John Rawls. 


\section{FAIR TRADE}

O movimento denominado Fair Trade ou na tradução para o português, Comércio Justo, surgiu na década de 50, ganhou força na década de 60 e tem sua origem na preocupação de um grupo de pessoas (consumidores), que preocupados com problemas ambientais, bem como com a dificuldade que pequenos produtores rurais encontravam com a expansão da agricultura e sua introdução no mercado de valores, como commodities (DAVIRON; VAGNERON, 2011).

O início de todo esse movimento ocorreu com a atuação de Franz van der Hoff e Nico Roozen, conhecedores da situação de produtores rurais mexicanos que não conseguiam viver de forma digna de seu trabalho, da exploração da cultura do café.

Ainda que à época existiam algumas ajudas, pelas entidades religiosas, estas não eram suficientes, nem mesmo eficientes, na medida em que necessitava-se de um sistema de cooperação entre os países do norte e do sul. Diante deste quadro, resolveram criar um projeto que permitisse que o mercado consumidor pudesse adquirir, por um preço justo, uma mercadoria produzida em condições éticas e respeito ao meio ambiente (ROOZEN; HOFF, 2002).

Com a implantação do comércio justo, a pratica comercial passou a ser feita diretamente entre produtores/distribuidores/consumidores. Em 1998 criou-se a primeira certificação de produtos FAIR TRADE, cuja iniciativa deve-se a algumas organizações holandesas, que passaram a comercializar o café mexicano, acima referido (RAYNOLDS, 2002).

Nota-se aqui, a existência de traços da denominada Teoria da Justiça, desenvolvida pelo filósofo americano John Rawls, ao defender algo como justo assim pontuou que: "algo é justo, por exemplo, um sistema social, se for aprovado por um espectador idealmente racional e imparcial que ocupa um ponto de vista geral e possui todo o conhecimento pertinente das circunstâncias" (RAWLS, 2002, p. 201)

A criação de uma certificação permitindo aos consumidores distinguir os produtos oriundos do mercado "comum" daqueles provenientes do comércio justo mostrou-se extremamente relevante para a sociedade, que já estava ciente e preocupada com os problemas ambientais e desigualdades sociais, neste sentido:

Na segunda metade dos anos 80, tal rede de difusão (Lojas do Mundo) passou a ser limitante para a crescente projeção e nasce, assim, a exigência de se

Revista de Direito, Economia e Desenvolvimento Sustentável | e-ISSN: 2526-0057 | Salvador | v. 4 | n. 1 | p. 
estender os pontos de venda à Grande Distribuição e às Redes Tradicionais. Com isto se tornou necessário "distinguir os produtos do comércio équo e solidário dos "coloniais" que já eram importados pela grande distribuição, aplicando sobre os primeiros uma "marca" que permitisse ao consumidor entender que "aqueles produtos" eram diferentes dos outros, exóticos e coloniais (CERATTI, 2002, p.78).

Atualmente, a principal certificadora mundial do fair trade é a Fairtrade Labelling Organizations International - FLO, entidade que engloba as principais associações ligadas ao Comércio Justo em todo o mundo e responsável por oitenta por cento do fair trade mundial. ${ }^{1}$

Visto a origem, resta conceituar o Fair Trade - Comércio Justo como um conjunto de práticas socioeconômicas, alternativas ao comércio nacional e internacional convencionais, cujas regras são globalmente injustas e, em particular, para produtores familiares rurais. As práticas do comércio justo e solidário devem estabelecer relações entre produtores e consumidores baseadas na equidade, parceria, confiança e interesses compartilhados, perseguindo os seguintes objetivos: obter condições mais justas para grupos de produtores marginalizados; e fazer evoluir suas práticas e regras com apoio dos consumidores. (TIBURCIO; VALENTE, 2007)

Acompanham o conceito BECCHHETTI e HUYBRECHTS ao definirem Fair Trade como uma parceria comercial, baseada em diálogo, transparência e respeito, que procura maior equidade no comércio internacional. Ele contribui com o desenvolvimento sustentável oferecendo melhores condições de comércio, e ao garantir os direitos dos produtores e trabalhadores marginalizados, especialmente no sul. (BECCHETTI; HUYBRECHTS, 2004).

\section{A International Federation of Alternative Trade (Federação Internacional de} Comércio Alternativo) define o Fair Trade como uma parceria comercial, baseada em diálogo, transparência e respeito, que busca maior equidade no comércio internacional, contribuindo para o desenvolvimento sustentável por meio de melhores condições de troca e garantia dos direitos para produtores e trabalhadores à margem do mercado, principalmente no Hemisfério Sul. $^{2}$

Nota-se que o fair trade baseia-se na transparência das relações, calcadas no respeito e equidade, visando sempre uma parceria proveitosa e justa a todos os envolvidos e respeito ao meio ambiente e a sociedade.

O sistema do comércio justo, mostra-se amparado pela teoria de Rawls:

Todos os valores sociais - liberdade e oportunidade, renda e riqueza, a as bases sociais do autorrespeito - devem ser distribuídos de forma igual, a não ser que uma distribuição desigual de um ou de todos esses valores seja vantajosa para 
todos. (RAWLS, 2000, p. 75)

\footnotetext{
$1 \overline{\text { https://www.fairtrade.net/about-fairtrade/fairtrade-system.html }}$ 2

http://www.sebrae.com.br/sites/PortalSebrae/artigos/o-que-e-fair-tradecomerciojusto,82d8d1eb00ad2410VgnVCM100000b272010aRCRD
} 
No Brasil, o comércio justo foi reconhecido e instituído legalmente pelo Decreto $\mathrm{n}^{\circ}$ 7.358 de 17 de novembro de 2010, que assim prevê:

Art. $2^{\mathrm{O}}$ Para os efeitos deste Decreto, entende-se por:

I - comércio justo e solidário: prática comercial diferenciada pautada nos valores de justiça social e solidariedade realizada pelos empreendimentos econômicos solidários; (grifo nosso).

Assim como as organizações internacionais e os estudiosos do tema, a legislação brasileira preocupou-se, ao conceituar o comércio justo, com os princípios intrínsecos ao fair trade, em total consonância com os preceitos constitucionais da ordem econômica, previstos no artigo 170 da Constituição Federal Brasileira.

O conceito de comércio justo é poliédrico, na medida em que pode ser dividido em quatro elementos principais, a saber: comércio; justiça; educação e informação, e; regulamentação.

Com relação ao elemento comércio, o que diferencia o produto comercializado no sistema do fair trade não é o produto em si, mas sim a maneira como ele é produzido e comercializado, visto que ele está diretamente conectado a um sistema sustentável e de preços e condições justas. (SILVA-FILHO; CANTLICE, 2011)

Já quanto à justiça, característica ligada tanto aos produtores quanto aos importadores dos produtos comercializados no fair trade, destaca-se o mutuo benefício aos players, uma vez que os produtores recebem remuneração justa e adequada por aquilo que produziram, enquanto os compradores têm um plus no negócio, como por exemplo um prêmio social, pré-financiamento. Isto tudo em prol do desenvolvimento socioeconômico. (op. cit.)

Por fim, em relação à educação, informação e regulamentação, o fair trade cumpre seu papel espalhando a mensagem de equidade nas relações comerciais, desde a sua origem até a ponta final da cadeia, na tentativa de regulamentar as trocas comerciais, para que estas ocorrem de forma mais equânime e justa.

Para que isto aconteça efetivamente, o comércio justo deve pautar-se em alguns princípios como o estabelecimento de relações diretas e de longo prazo entre produtores e compradores, limitando ao máximo o número de intermediários; o pagamento de um preço justo, incluindo os custos da matéria-prima, dos meios de produção e do tempo de trabalho, os custos sociais e ambientais, que permita aos produtores e às famílias viver dignamente; o 
respeito às condições de trabalho estabelecidas em normas internacionais ou nas do próprio país, se forem melhores; o acesso a um pré-financiamento antes da colheita, caso seja solicitado ao comprador; os modos de produção que respeitem o meio ambiente, condição essencial para o desenvolvimento sustentável; o respeito às normas ambientais, sociais e de comercialização solidária; e as informações aos consumidores sobre os produtores e os produtos comercializados. (JOHNSON, 2004)

Os princípios que sustentam o comércio justo demonstram a preocupação deste modelo de negócios não só com os lucros, que são inerentes à toda atividade econômica/empresarial, mas também com toda a cadeia de produção, com as pessoas envolvidas, visando sempre um bem-estar aos players, ao meio-ambiente, ao próprio mercado, bem como à toda a população envolvida.

Sem a existência dos princípios, o comércio justo poderia não funcionar, acarretando, possivelmente, um desvirtuamento de seus ideais, ressaltando assim a importância dos seus princípios:

\begin{abstract}
O comércio justo, ético e solidário, está baseado em princípios como a erradicação do trabalho infantil e do trabalho escravo, a eliminação das discriminações de raça, gênero e religião, a preservação da saúde das pessoas e do ambiente, a eliminação dos níveis de intermediação comercial especulativa, a garantia do pagamento de preços justos aos produtores, o respeito aos direitos trabalhistas, o respeito às identidades históricas e culturais, locais e regionais, a valorização das dimensões não geográficas do território, o fortalecimento das capacidades de escolha e planejamento das pessoas, o estímulo à criação de associações e cooperativas, o apoio ao desenvolvimento e a oferta de ferramentas de conhecimento e de tomada de decisão, a garantia dos fluxos multidirecionais de informações entre os atores envolvidos, entre tantos outros. (SAMPAIO; FLORES, 2002, p. 15)
\end{abstract}

O modelo do fair trade, sem dúvidas, pode ser caracterizado como instrumento de busca da justiça social, na medida em que permite aos envolvidos atuar em melhores condições, dentro de um sistema previamente definido, com a finalidade de propiciar ao mercado e aos seus players igualdade, sustentabilidade e justiça.

Neste sentido Rawls (2000, p. 17):

(...) procuramos de fato é uma divisão institucional do trabalho entre a estrutura básica e as regras aplicáveis diretamente aos indivíduos e às associações, que eles devem seguir nas suas transações particulares. Se a divisão do trabalho puder ser estabelecida, os indivíduos e associações estarão livres para buscar suas metas de forma mais eficaz, no âmbito da estrutura básica, com a segurança de saber que, em outra parte no sistema social, são efetuadas as correções para garantir a justiça do contexto. 
A maneira de atuar no sistema do fair trade tem grande relação com a denominada economia solidária, que é o:

conjunto de experiências coletivas de trabalho, produção, comercialização e crédito, organizadas por princípios solidários e que aparecem sob diversas formas: cooperativas e associação de produtores, empresas autogestionárias, bancos comunitários, clubes de troca, e diversas organizações populares urbanas e rurais (SINGER; SOUZA, 2000, p. 123)

No fair trade, o consumo dos produtos não encerra a cadeia de produção, simplesmente, posto que o ato de consumir pode implicar em um reposicionamento da figura do consumidor. Dessa forma demonstra-se ao consumidor que a mercadoria por ele adquirida não encerra sua função ali, mas também revela os efeitos que o ato de consumir produz sobre a sociedade, estabelecendo um link entre o produtor e o consumidor, incentivando setores sociais que estão em desvantagem econômica, permitindo-se, assim, uma recusa aos produtos oriundos de empresas despreocupadas com as questões primárias da sociedade. (GOODMAN, 2003)

A ideia do comércio justo tem semelhança com as bases da economia colaborativa, conforme se verá a seguir, bem como com a Teoria da Justiça de Rawls, uma vez que o propósito de sua teoria é a de reger: "as desigualdades de perspectivas de vida entre cidadãos, resultantes das posições sociais de partida, das vantagens naturais e das contingências históricas". (RAWLS, 2000, p. 19-20)

\section{ECONOMIA COLABORATIVA}

A economia colaborativa surge diante de uma necessidade socioambiental, em razão do aumento do consumo desenfreado, empobrecimento das relações pessoais/sociais, além dos impactos ambientais causados.

Este ato de consumir "irresponsavelmente" virou rotina, passando a ser um comportamento automático, impedindo o consumidor a refletir sobre os impactos deste tipo de conduta na vida privada, comunitária e social, tornando-os reféns do consumo (BOTSMAN e ROGERS, 2011).

Entretanto, o comportamento "irresponsável" do consumidor não é um ato de má-fé, na medida em que ele encontra-se inserido em uma sociedade capitalista e individualista, neste sentido: 
Por outro lado, a "necessidade" de consumir tornou-se uma questão de inclusão e ascensão social, numa cultura que acentua a desigualdade, o egoísmo, a competitividade, a violência, a intolerância, e afasta a sociedade do crescimento saudável e solidário. (CAMPELLO; SANTIAGO, 2016, p.142)

O filósofo francês Gilles Lipovetsky caracteriza empiricamente a sociedade de consumo por diferentes traços:

Elevação do nível de vida, abundância das mercadorias e dos serviços, culto dos objetos e dos lazeres, moral hedonista e materialista etc. Mas, estruturalmente, é a generalização do processo de moda que a define propriamente. A sociedade centrada na expansão das necessidades é, antes de tudo, aquela que reordena a produção e o consumo de massa sob a lei da obsolescência, da sedução e da diversificação, aquela que faz passar o econômico para a órbita da forma moda. (LIPOVETSKY, 2009, p. 184).

Nesse sentido, temos que a atual sociedade de consumo é aquela que não se importa com as necessidades reais para uma existência digna e sim com a adequação à "moda", ou seja, o que importa é atender aquilo que é imposto pela mídia em geral, pelo mercado de consumo e até pela própria sociedade consumista, como sendo o correto, o melhor, o necessário. Assim e somente dessa maneira, o indivíduo é reconhecido como ser existente em sociedade; as necessidades individuais, os valores subjetivos de cada um deixam de ser o necessário, passando a importar somente o que é dito e por que não, o que é imposto pela "moda".

A sociedade de consumidores é uma realidade atual, cada dia mais perceptível e ao mesmo tempo perigosa, pois propõe as pessoas o surgimento incessante de necessidades, com promessas de satisfação pessoal e social, com felicidade garantida a cada nova compra. Essa "promessa" do consumo de uma nova vida ao consumidor, de um reconhecimento e de um renascimento em sociedade, é exatamente o que levam as pessoas a depender de forma tão significativa do consumo de produtos e serviços.

O valor mais característico da sociedade de consumidores, na verdade seu valor supremo, em relação ao qual todos os outros são instados a justificar seu mérito, é uma vida feliz. A sociedade de consumidores talvez seja a única na história humana a prometer felicidade na vida terrena, aqui e agora e a cada "agora" sucessivo. Em suma, uma felicidade instantânea e perpetua. Também é a única sociedade que evita justificar e/ou legitimar qualquer espécie de infelicidade (exceto a dor infligida aos criminosos como "justa recompensa" por seus crimes), que recusa-se a tolerá-la e a apresenta 
como uma abominação que merece punição e compensação (BAUMAN, 2008, p. 60).

Segundo o sociólogo e filósofo francês Jean Baudrillard:

Todo o discurso sobre as necessidades assenta numa antropologia ingênua: a proteção da propensão natural para a felicidade. Inscrita em caracteres de fogo por detrás da menos publicidade para as Canárias ou para os sais de banho, a felicidade constitui a referência absoluta da sociedade de consumo, revelando-se como o equivalente autêntico da salvação (BAUDRILLARD, 2007, p. 47).

Baudrillard ainda ressalta a importância da relação estabelecida entre o mito da felicidade prometida pela sociedade de consumo e o mito da igualdade, ou seja, para que a felicidade seja o veículo do mito igualitário, ela deve ser mensurável, representando o bemestar do consumidor por objetos e signos, devendo ser visível a todos; assim, a felicidade na sociedade de consumo deve ser provada, como exigência, no ideal de consumo, de igualdade ou distinção. A felicidade não representaria mais um estado interior, próprio de cada ser humano, sem necessidade de provas; ao contrário, ela deve ser ostentada para a sociedade através da posse e utilização dos bens de consumo (BAUDRILLARD, 2007, p. 47-48).

Apesar da responsabilidade que o comportamento do consumidor gera nas questões socioambientais, é insuficiente para o exame da lógica do consumo, examinar somente o seu comportamento individual, uma vez que é imprescindível a análise social deste modo de agir, deixando em segundo plano a sua psique. (BAUMAN, 2007 apud SANTIAGO; CAMPELLO, 2016)

Diante disso, surge o movimento da economia colaborativa, pelo qual a ideia é compartilhar e não possuir. Produtos passam a ser usados sob a lógica de serviço: o consumidor paga para usufruir do benefício do objeto por meio de empréstimo, troca, aluguel e compartilhamento. A tendência também reinventa a forma como as pessoas usam seu tempo e trocam conhecimento. (GANSKY, 2011 p. 1 e 2).

Para melhor entender, pode-se conceituar economia colaborativa como:

A economia de compartilhamento é um ecossistema socioeconômico construído em torno da partilha de recursos humanos e físicos. Ela inclui a criação, produção, distribuição, comércio e consumo compartilhados de bens e serviços por diferentes pessoas e organizações (MATOFSKA, 2014)

Neste mesmo sentido:

Já é realidade, em diferentes partes do mundo, uma outra espécie de economia, gestada a partir de iniciativas, sobretudo de natureza cooperativista e associativista, oriundas da sociedade civil e dos meios 
populares. Mostra-se sob diferentes configurações: criação coletiva do próprio circuito de produção e consumo, alimentando cadeias socioprodutivas autônomas e, em alguns casos, não-monetarizadas, ou diferentes tipos de parcerias com os poderes públicos. É o que se chama de economia colaborativa-solidária. Como exemplos, projetam-se os bancos populares, clubes de trocas e as cooperativas sociais (FRANÇA FILHO, 2004. p. 15 apud CAMPELLO; SANTIAGO, 2016)

Essa preocupação das pessoas com questões socioambientais e socioeconômicas são o start para busca da justiça social, conforme Rawls (2000, p. 18): "atitudes sociais de ajuda e estímulo e as instituições encarregadas de seu aprendizado e de sua utilização."

E continua o filósofo: "A capacidade desses cidadãos entenderem, aplicarem e atuarem conforme uma concepção pública de justiça, está implícita no exercício deles de pensamento, do qual, por sua vez, deriva o senso de justiça." (RAWLS, 2002, p. 51).

Os benefícios do compartilhamento mostram-se favoráveis, uma vez que conectam pessoas, otimizam tempo e geram economia, sem mencionar-se os pontos positivos gerados em toda a cadeia de consumo, como por exemplo a flexibilidade nos negócios para as empresas, conforme ensina BELK (2013, p. 5):

O compartilhamento faz um grande sentido prático e econômico para o consumidor, o meio ambiente e a comunidade. Também pode fazer uma grande dose de bom senso para os negócios que são suficientemente flexíveis, inovadores e com visão de futuro.

Os negócios gerados com fundamento na economia de compartilhamento acarretam um consumo colaborativo, que, por sua vez, permite aos os consumidores vislumbrar os ganhos de acesso ao uso de produtos e serviços, ao invés de simplesmente possuí-los. É assim que os indivíduos ganham tempo, dinheiro, além de economizar espaço, o que permite-lhes fazer novas conexões e relacionamentos, acarretando um consumo mais ativo e consciente (BOTSMAN; ROGERS, 2011).

Mais importante, neste estudo, do que os benefícios empresariais, são os ganhos sociais que a economia colaborativa traz, especialmente naquilo que diz respeito às questões de solidariedade, neste sentido:

Do ponto de vista da solidariedade e do desenvolvimento social, pode-se visualizar indivíduos engajando-se voluntariamente em projetos coletivos concretos, emanados do seio da sociedade civil, e não meramente assistencialistas e passivos, o que também representa um avanço em relação à solidariedade tradicional, típica de grupos primários, a medida que a organização não se fecha num pequeno grupo de beneficiários (FRANÇA FILHO, 2004, p. 20 apud CAMPELLO; SANTIAGO, 2016) 
A economia colaborativa traz consigo quatro princípios fundamentais que: a massa crítica, a capacidade ociosa, a crença no bem comum e a confiança entre desconhecidos. (BOTSMAN; ROGERS, 2011)

Em linhas gerais, sobre os princípios, a massa crítica refere-se à escolha do consumidor, bem como no exemplo dela; já a capacidade ociosa diz respeito à utilidade, tempo de uso de algum produto durante toda a sua vida; o princípio da crença no bem comum consiste na troca de informações que acredita-se ser útil a todos e, finalmente; a confiança relaciona-se em ter que acreditar/confiar em terceiro desconhecido.

Superados estes pontos, tem-se que a economia colaborativa deve, também, ser vista sob o ponto de vista social, na medida que, assim como o fair trade, ela causa impactos na forma de relacionamento das pessoas, da sociedade em geral, do meio ambiente, além das próprias empresas.

No passado recente, constatou-se que o avanço da tese do livre mercado em nível mundial, bem como a diminuição da presença regulatória do Estado. De olho neste cenário, empresas capitalistas e o próprio Estado valeram-se de medidas políticas que, em conjunto, criaram uma nova forma de capitalismo, cuja característica é a globalização das atividades econômicas centrais, com flexibilização organizacional e valorização do capital, em detrimento do trabalho. Além disso, a própria globalização enseja a criação de padrões de comportamentos, na medida em que espalha um sistema produtivo baseado em novas tecnologias, excluindo, assim, as barreiras físicas (CASTELLS, 2005).

Com isso, apesar do ganho financeiro, ainda que para uma minoria, problemas:

A abundância dos bens de consumo, símbolo do capitalismo moderno, já é objeto de críticas que alçam o consumismo como um dos principais problemas da sociedade moderna, repercutindo fortemente na crise ambiental. Tratar do consumismo passou a significar também uma contribuição para a construção de uma sociedade mais sustentável (PORTILHO, 2010 apud CAMPELLO; SANTIAGO, 2016, p. 67).

E continua:

A incorporação das questões relacionadas ao consumo aos crescentes movimentos sociais, como o ecológico, acendeu o debate sobre o consumo ambientalmente consciente que, posteriormente, evoluiu para a ideia de consumo social e politicamente responsável. O objetivo é colaborar para que a soberania do consumidor, propagada pelo neoliberalismo, converta-se em cidadania do consumidor, instrumento de ativa prática social, política e ecológica (op. cit.)

As consequências deste comportamento, causa a um empobrecimento dos vínculos 
sociais. Nesse terreno, a insegurança e a falta de objetivos pontuam o comportamento individual, enquanto que, no campo social, esvazia-se a sua coesão.

Assim, nota-se que a sociedade capitalista de acúmulo de capital não tinha qualquer preocupação com a sociedade ao seu entorno, muito menos com o planeta. Seu único objetivo é atingir o lucro que seja capaz de satisfazer seus egos, na tentativa de se alcançar um desenvolvimento econômico maior e melhor a todo momento, independente dos custos destes atos.

É por esta razão que a economia colaborativa tem papel relevante, uma vez que o consumidor, bem como todos os agentes da cadeia de produção, devem conscientemente fazer melhores escolhas, posto que inseridos em ambiente coletivo, e essas escolhas influenciam o meio em que vivem.

É com esta missão que a economia colaborativa serve de mecanismo ideário da justiça social, proposta por Rawls, na medida em que busca-se, neste sistema de economia, uma forma de igualdade e condições a todos, diminuindo as desigualdades sociais, proporcionando vantagens aos membros da sociedade, conforme se extrai dos princípios de justiça:

(1) Cada pessoa tem direito igual a um sistema plenamente adequado de liberdades e direitos básicos iguais para todos, compatíveis como um mesmo sistema para todos. (2) As desigualdades sociais e econômicas devem preencher duas condições: em primeiro lugar, devem estar ligadas a funções e posições abertas a todos em condições de justiça (fair) igualdade de oportunidades; e, em segundo lugar, devem proporcionar a maior vantagem para os membros mais desfavorecidos da sociedade. (RAWLS, 2000, p. 208)

Todavia, há apenas uma crença de que a economia colaborativa ajudará a reduzir os problemas ambientais e sociais, entretanto, quase não há estudos sobre o seu impacto e relação direta ao consumo mais consciente e sustentável. (SCHOR, 2016).

\section{RESPONSABILIDADE SOCIAL E SOLIDÁRIA DA EMPRESA}

Diante do conhecimento do fair trade e da economia colaborativa, resta enquadrar a função social e solidária da empresa neste contexto, uma vez que ela detém papel relevante na construção de ambos os sistemas, com vistas ao conceito de justiça social proposto por 
Rawls.

Neste diapasão, é necessário apontar que os mercados (como instituições) não podem ser vistos como pontos de encontro - neutros e impessoais - entre o binômio oferta/demanda oriundos de sujeitos cujas relações limitam-se às que advém dos sinais que recebem do funcionamento do sistema de preços, concebido pela economia neoclássica. Ao contrário, as empresas são estruturas sociais, isto é, formas recorrentes e estáveis de interação, submetidas a sanções (SWEDBERG, 2005).

Assim, pode-se afirmar que tanto o fair trade quanto o sistema de economia colaborativa são o:

conjunto de experiências coletivas de trabalho, produção, comercialização e crédito, organizadas por princípios solidários e que aparecem sob diversas formas: cooperativas e associação de produtores, empresas autogestionárias, bancos comunitários, clubes de troca, e diversas organizações populares urbanas e rurais (SINGER; SOUZA, 2000, p.123).

Em resumo, trata-se de um movimento de um grupo (trabalhadores, consumidores, etc.), intervindo na produção de sua história e procurando apresentar projetos para a sociedade, como por exemplo experiências participativas abordam a economia distributiva operada pelo Estado, responsável por organizar a produção da riqueza social.

Deve-se, com isso, valorizar-se os espaços de reprodução da vida e convivência humana, com intima relação nas redes de trocas entre indivíduos ou grupos. Resgata-se, assim, o valor social e a dimensão pública do território, como espaço da interação e da troca, mesmo porque:

(...) uma vez que o poder político é sempre coercitivo - apoiado no monopólio que o Estado tem da força legal -, num regime democrático ele é também o poder do público, isto é, o poder dos cidadãos livres e iguais como um corpo coletivo. Mas, se cada cidadão tem uma mesma parcela de poder político, então, na medida do possível, o poder político deveria ser exercido, pelo menos quando os elementos constitucionais essenciais e questões de justiça básica estão em discussão, de uma maneira que todos os cidadãos possam endossar publicamente à luz de sua própria razão. (RAWLS, 2003, p. 128)

É neste aspecto que enquadra-se a empresa, quando analisada sob o enfoque de sua responsabilidade social e solidária, uma vez que ela é instrumento legal para o exercício de iniciativas econômicas. Dessa forma, justo é que à ela seja reconhecida a sua função social, na medida em que a Constituição da República define que a livre iniciativa deve ter um valor social. 
Neste sentido:

Se a livre iniciativa é a possibilidade de agir antes de qualquer outro, sem influência externa, como uma expressão da liberdade, o valor social, no caso, significa que essa atividade deve ser socialmente útil e que se procurará a realização da justiça social, do bem-estar social (CRETELLA JR.,1992, p. 140-141 apud SANTIAGO; CAMPELLO, 2016).

Diante do que se extrai da Constituição Federal, o direito privado tem fundamento de validade na função social e na solidariedade, na medida em que a República Federativa do Brasil tem por fundamento o princípio da dignidade da pessoa humana, bem como tem por objetivos construir uma sociedade solidária, através da justiça social (PAYÃO; SANTIAGO, 2016).

Maria Helena Diniz (1998, p. 613) define a função social da empresa como "o exercício pelo administrador da sociedade por ações das atribuições legais e estatutárias para a consecução dos fins e do interesse da companhia, usando do seu poder de modo a atingir a satisfação das exigências do bem comum".

Nota-se que a empresa tem sua finalidade precípua que é circular bens e serviços, buscando lucros. Todavia, a par desta busca, deve-se também, buscar a melhora nos contingentes da sociedade em que inserida, atingindo assim, a completude de sua missão constitucional.

A função social da empresa possui o mesmo sentido, ou seja, a empresa deve cumprir com as finalidades principais para as quais fora estruturada, uma vez que são úteis ao desenvolvimento econômico do país. Por outro lado, não pode atuar inerte á realidade social, educacional, cultural do meio em que se encontra, devendo contribuir com o cumprimento dos direitos e objetivos constitucionais, que, por óbvio, vão além do estatuto da empresa. (PAYÃO; SANTIAGO, 2016, p.1125)

Dessa forma, a empresa, para realizar a sua função social, deve compatibilizar os interesses próprios (individuais e privados), com os interesses coletivos, uma vez que o Estado, por si só, não tem condições de realizar todas as necessidades sociais. Logo, a consecução dos objetivos primários da empresa (função econômica e financeira) deve coadunar-se com a sua função eminentemente social. (PAYÃO; SANTIAGO, 2016).

Além da função social, a empresa também tem que ter responsabilidade solidária, que nas palavras de Paulo Luiz Netto Lôbo (2009, p. 81):

Como categoria ética e moral que se projetou para o mundo jurídico, significa um vínculo de sentimento racionalmente guiado, limitado e autodeterminado que impõe a cada pessoa deveres de cooperação, 
assistência, amparo, ajuda e cuidado em relação às outras. A solidariedade cresce de importância na medida em que permite a tomada de consciência da interdependência social.

A atividade econômica deve pautar-se sempre pela honestidade, boa-fé e cidadania, uma vez que a empresa e sua atividade tem papel relevante no modo de vida da sociedade em que atua, como visto nos exemplos do fair trade e na economia colaborativa.

Assim, a função solidária deve estar intrinsecamente arraigada no modo de operar das empresas, para que então atinja seu papel constitucional.

A função solidária da empresa expressa justamente a junção dos conceitos de solidariedade e cidadania na atividade econômica, ao lado da função social da empresa, busca uma atuação mais humana na atividade empresarial, uma atuação mais positiva, com ações concretizadas. (PAYÃO; SANTIAGO, 2016, p. 1129).

Nota-se que, apesar de ser um conceito abstrato, as ações voltadas à realização da função solidária da empresa são simples e, devem iniciar-se no seu interior, ao oferecer condições salubres e seguras de trabalho, instalações adequadas. Além disso, conferindo direitos aos familiares de seus colaboradores; proteção ao meio ambiente etc.

Nesse sentido Manoel de Queiroz Pereira Calças e Simone Bento (2015, p. 28) explicam:

A empresa pode agir com responsabilidade solidária direcionando suas ações para seus próprios empregados, como, por exemplo, ensejando boas condições no local de trabalho, conforto, qualidade de material, segurança, salários justos e incentivadores, plano de carreira, treinamento tecnológico, atividades educacionais, culturais e de lazer, contratação de deficientes e idosos. As ações da empresa podem também se dirigir aos familiares de seus empregados, fornecendo clubes para lazer e prática de esportes, creches, escolas, planos de saúde, educação continuada etc. O respeito aos direitos humanos como não exploração de mão-de-obra infantil, não utilização do chamado trabalho escravo, adoção de conduta baseada na igualdade das pessoas, sem levar em conta a diferença de sexo, religião, nacionalidade ou raça.

A função solidária da empresa exige que os deveres dela sejam mais do que os seus compromissos de mercado, mas também as suas iniciativas voluntárias que beneficiem a comunidade, com respeito ao próximo. Assim, a empresa deve compatibilizar seus interesses pessoais com os interesses sociais, na busca da justiça social. (PAYÃO; SANTIAGO, 2016).

Dessa forma, para que a atividade empresarial seja considerada legítima, de acordo com os preceitos constitucionais, ela deve atuar com estrita observância da sua responsabilidade social e solidária, com vistas aos ditames da justiça social, expressamente previsto no artigo 170 da Constituição da República. 
$\mathrm{Na}$ medida em que a justiça social tem sua conformação na própria dignidade da pessoa humana, como fim da ordem econômica (GRAU, 2010, p. 228), deve ser buscada pela empresa a todo momento.

De acordo com Rawls (2000, p. 145): "(...) Uma concepção do justo é um conjunto de princípios, gerais em sua forma e universais em sua aplicação, que deve ser publicamente reconhecido como uma última instância de apelação para a ordenação das reivindicações conflitantes de pessoas éticas (...)".

Assim, a empresa ao atuar em conformidade com as normas, bem como com atenção à sua função social e solidária, estará sempre atuando conforme os ditames da justiça social.

\section{CONSIDERAÇÕES FINAIS}

A ordem econômica constitucional brasileira, com fundamento no artigo 170 da Constituição Federal de 1988, deve pautar-se segundo os ditames da justiça social, cujo conteúdo é muito bem explorado e definido pelo filósofo americano John Rawls.

O sistema do fair trade ou comércio justo, criado a partir da preocupação com as desigualdades existentes no mercado mundial, especialmente quanto às questões de produção sustentável, condições sociais e econômicas da sociedade envolvida, desempenha papel fundamental na luta pela justiça, na medida em que consegue impor aos players do mercado, o pagamento justo pelos produtos certificados, com a consequente melhoria na qualidade de vida daqueles envolvidos e dos que estão ao seu redor.

Já a economia colaborativa, também em razão dos problemas da modernidade, tais como diferenças sociais e econômicas e questões ambientais, instaurando a ideia de compartilhar ao invés de ter/possuir, permitindo, então que um maior número de pessoas possa ter acesso a bens e serviços, antes considerados exclusivos ou de difícil acesso.

Assim, podemos chegar ao fenômeno da exclusão social e a primeira necessidade latente que surge na tentativa de abolir tal fenômeno é exatamente a proteção do vulnerável, 
a efetivação mais abrangente possível da igualdade social para a concretização da dignidade da pessoa humana que necessita viver em sociedade.

A necessidade de consumir para existir socialmente acaba marginalizando aqueles que não estão dentro dos padrões aceitos pela maioria como melhores, corretos ou normais; são eles, que não possuem uma boa condição financeira para arcar com suas dívidas essenciais e garantir acesso aos mais diversos itens de consumo.

Neste sentido, a empresa, principal responsável pela circulação da economia, deve observar em seu modo de atuação, a sua responsabilidade social e solidária, uma vez que, para coadunar-se com a ordem constitucional, necessita exercer seu papel de agente transformador da sociedade e, não só buscar o lucro.

Assim, a empresa quando atua em conformidade com o texto constitucional, atendendo aos objetivos principais e secundários (lucro e função social/solidária), tal qual como ocorre no sistema do fair trade e da economia colaborativa, atuará conforme os ditames da justiça social, podendo considerá-la como uma empresa constitucional.

\section{REFERÊNCIAS}

ARAUJO, Luiz Alberto David; JÚNIOR, Vidal Serrano Nunes. CURSO DE DIREITO CONSTITUCIONAL. $8^{\text {a }}$ edição. São Paulo: SARAIVA, 2004.

BAUDRILLARD, Jean. A sociedade de consumo. Tradução Artur Morão. Lisboa/Portugal: Edições 70, 2007.

BAUMAN, Zygmunt. Vida para Consumo: a transformação das pessoas em mercadorias. Tradução Carlos Alberto Medeiros. Rio de Janeiro: Jorge Zahar Ed., 2008.

BECCHETTI, Leonard; ADRIANI Fabrizio. Fair Trade: A 'Third Generation' Welfare Mechanism to make Globalization Sustainable. CEIS Working Paper No 62. 2004. Disponível em: <https://ssrn.com/abstract=625562>. Acesso em 18. jan. 2018.

BECCHETTI, Leonard; HUYBRECHTS; Benjamin. The dynamics of fair trade as a mixed-form market. Journal of Business Ethics, Holanda, v. 81, n. 4, p. 733-750, 2008. Disponível em: <https://doi.org/10.1007/s10551-007-9544-8>. Acesso em 18. jan. 2018.

BELK, Russel. W. You are what you can access: Sharing and collaborative consumption online. Journal of Business Research, v.67, n. 8, 2013. Disponível em: <https://www.sciencedirect.com/science/article/pii/S0148296313003366>. Acesso em 20 jan 2018. 
BOSTMAN, Rachel; ROGERS, Roo. O que é meu é seu: como o consumo colaborativo vai mudar o nosso mundo. Trad. Rodrigo Sardemberg. Porto Alegre: Bookman, 2011.

BRASIL. Constituição Federal de 1988. Promulgada em 5 de outubro de 1988.

BRASIL. Decreto $\mathbf{n}^{\circ} 7.358$ de 17 de novembro de 2010. Publicado em 18 de novembro de 2010.

BULOS, Uadi Lammêgo. Curso de direito constitucional. 8. ed. rev. e atual. de acordo com a Emenda Constitucional n. 76/2013. São Paulo: Saraiva, 2014.

CALÇAS, Manoel de Queiroz Pereira; BENTO, Simone. A Empresa: Responsabilidade Solidária e $\quad$ Sustentabilidade. Disponível em $\quad$ http://ww

CAMPELlO, Lívia Gaigher Bósio; SANTIAGO, Mariana Ribeiro. O Consumo Colaborativo e Sustentável na Sociedade da Informação. III Encontro de internacionalização do conpedi - Madrid, 2016. Disponível em < http://portaltutor.com/index.php/conpedireview/article/viewFile/43/40>. Acesso em 21 jan. 2018.

CANOtilho, J.J. Gomes. Direito Constitucional e Teoria da Constituição. Coimbra: Almedina, 2000.

CASTELLS, Manuel. O poder da identidade. 3. ed. São Paulo: Paz e Terra, 2002. A sociedade em rede. 8 ed. São Paulo: Paz e Terra, 2005.

CERATTI, Federico. O comércio équo e solidário. In $F R A N C ̧ A$, Cássio Luiz (Org). Comércio Ético e Solidário. São Paulo, Fundação Friedrich Ebert, 2002.

DAVIRON, Benoit; Vagneron, Isabelle. From commoditisation to de-commoditisation... and back again: Discussing the role of sustainability standards for agricultural products. Development Policy Review, v. 29, 2011. Disponível em: <http://onlinelibrary.wiley.com/doi/10.1111/j.1467-7679.2011.00515.x/pdf>. Acesso em 17. jan. 2018.

DINIZ, Maria Helena. Dicionário jurídico. São Paulo: Saraiva, vs. 2-4, 1998.

EFTA - EUROPEAN FAIR TRADE ASSOCIATION. Disponível em: <http://www.eftafairtrade.org/>. Acesso em 19. jan. 2018.

GANSKY, Lisa. Mesh - Porque o Futuro dos Negócios é Compartilhar. Rio de Janeiro: Alta Books: 2011.

GENDRON, Corinne; BISAILLON, Véronique; RANCE, Ana Isabel Otero. The Institutionalization of Fair Trade: More than Just a Degraded Form of Social 
Action.

A.I.O. J Bus Ethics (2009) 86(Suppl 1): 63. Disponível em: <https://doi.org/10.1007/s10551008-9758-4>. Acesso em 18. jan. 2018.

GOODMAN, Michel K. Reading fair trade: political ecological imaginary and the moral economy of fair trade foods. Santa Cruz: University of California, 2003. Disponível em < https://doi.org/10.1016/j.polgeo.2004.05.013> Acesso em 18. jan. 2018.

GRAU, Eros Roberto. A ORDEM ECONÔMICA NA CONSTITUIÇÃO DE 1988. $14^{\mathrm{a}}$ edição. São Paulo: MALHEIROS, 2010.

JOHNSON, Pierre W. (org). Comércio Justo e Solidario. Cadernos de Proposições para o Século XXI. Aliança por um Mundo responsável, Plural e Solidário. Trad. Guilherme João de Freitas Teixeira. São Paulo, Instituto Polis, 2004.

LIPOVETSKY, Gilles. O império do efêmero: a moda e seu destino nas sociedades modernas. Tradução Maria Lucia Machado. São Paulo: Companhia das Letras, 2009.

LÔBO, Paulo Luiz Netto. Direito civil: parte geral. São Paulo: Saraiva, 2009.

LOPES PINTO, João R. Economia solidária: de volta à arte da associação. Porto Alegre: Ed. UFRGS, 2006.

MATOFSKA, Benita. What is the sharing economy? The People Who Share Blog. 2014. Disponível em: < http://www.thepeoplewhoshare.com/blog/what-is-the-sharing-economy/>. Acesso em 21 jan. 2018.

PAYÃO, Jordana Viana; SANTIAGO, Mariana Ribeiro. A FUNÇÃO SOCIAL E SOLIDÁRIA DA EMPRESA NO ÂMBITO DAS RELAÇÕES DE TRABALHO. Revista

Direito da Cidade, vol. 08. n. 3 ISSN 2317-7721. 2016. Disponível em < http://www.epublicacoes.uerj.br/index.php/rdc/article/view/22109>. Acesso em 22 jan. 2018.

RAYNOLDS, Laura. Consumer/Producer Links in Fair Trade Coffee Networks. Sociologia Ruralis, 42: p. 404-424. 2002. Disponível em: <http://onlinelibrary.wiley.com/doi/10.1111/1467-9523.00224/pdf〉. Acesso em 17. jan. 2018.

RAWLS, John. Justiça e Democracia. Trad. Irene A. Peternot. São Paulo: Martins Fontes, 2000.

Uma Teoria da Justiça. Trad. Almiro Piseta e Lenita Maria Rímoli Esteves.

2 ed. São Paulo: Martins Fontes, 2002.

Justiça como Equidade: uma reformulação. Trad. Claudia Berliner. São Paulo: Martins Fontes, 2003.

ROOZEN, Nico; VAN DER HOFF, Frans; L'aventure du commerce équitable: une

Revista de Direito, Economia e Desenvolvimento Sustentável | e-ISSN: 2526-0057 | Salvador | v. 4 | n. 1 | p. 
alternative à la mondialisation par les fondateurs de Max Havelaar, Ed. Jean-Claude Lattès, 2002.

SAMPAIO, Felipe; FLORES, Murilo. Comércio Ético e Solidário e a agricultura familiar brasileira: Um outro mercado é possível? In FRANÇA, Cássio Luiz (Org). Comércio Ético e Solidário. São Paulo, Fundação Friedrich Ebert, 2002.

SANTIAGO, Mariana Ribeiro; CAMPELLO, Livia Gaigher Bósio. Função social e solidária da empresa na dinâmica da sociedade de consumo. Scientia Iuris, Londrina, v. 20, n. 1, p.119-143, abr. 2016. Disponível em <DOI: 10.5433/2178-8189.2016v20n1p119>. ISSN:

2178-8189. Acesso em 22 jan. 2018.

SANTIAGO, Mariana Ribeiro; BEZERRO, Eduardo Buzetti Eustachio. RELAÇÕES DE CONSUMO NA PÓS-MODERNIDADE: O CONSUMO COLABORATIVO COMO

INSTRUMENTO DE SUSTENTABILIDADE. Revista de Direito da Cidade, vol. 09. n. 2. ISSN 2317-7721. 2017. Disponível em < DOI: 10.12957/rdc.2017.26970>. Acesso em 23 jan. 2018.

SCHOR, Juliet. Debating the sharing economy. Journal of Self-Governance and Management Economics, v. 4, n. 3, p. 7-22, 2016. Disponível em: $<$ https://www.ceeol.com/search/article-detail?id=430188 > Acesso em 20 jan. 2018.

Paradoxes of openness and distinction in the sharing economy. Poetics, V. 54, p. 66-81, 2016. < https://doi.org/10.1016/j.poetic.2015.11.001>. Acesso em 20 jan. 2018.

SILVA-FILHO, José Carlos Lazaro; CANTALICE, Flavio Leandro Batista de Moura. Fair Trade (comércio justo) como um "Tópico Quente" internacional e sua abordagem no Brasil. Revista Eletrônica de Estratégia \& Negócios, [S.1.], v. 4, n. 2, p. 223-244, dez. 2011.

SINGER, Paul; SOUZA, André Ricardo de. A economia solidária no Brasil: a autogestão como resposta ao desemprego. São Paulo: Contexto, 2000.

SWEDBERG, Richard. Markets in society In SMELSER, Neil J.; SWEDBERG, Richard. The handbook of economic sociology. 2. ed. Princeton: Princeton University Press e Sage Editions, 2005.

TIBURCIO, Breno Aragão; VALENTE, Ana Lucia E. F. O comércio justo e solidário é alternativa para segmentos populacionais empobrecidos? Estudo de caso em Território Kalunga (GO). Rev. Econ. Sociol. Rural [online]. 2007, vol.45, n.2, pp.497-519. ISSN 0103- 2003. Disponível em <http://dx.doi.org/10.1590/S0103-20032007000200010.>. Acesso em 19. jan. 2018.

URIARTE, Alex. Fair Trade: uma introdução e algumas reflexões. Disponível em: <http://www.bsd-net.com/bsd_brasil/fairtrade.html>. Acesso em 17.jan. 2018. 